\title{
URBAN BUILT-UP AND LEADER IN ENERGY AND ENVIRONMENTAL DESIGN (LEED) CERTIFICATION: A CASE STUDY OF NATIONAL CAPITAL TERRITORY (NCT) OF DELHI, INDIA
}

\author{
Sandesh Yada ${ }^{1} v$, Haseena Hashi ${ }^{2} a$ and Shams Perwaiz ${ }^{3}$ \\ ${ }^{1}$ Research Scholar, ${ }^{2}$ ICSSR Senior Fellow \\ Department of Geography, Jamia Millia Islamia, Delhi, India \\ ${ }^{3}$ Teacher, Sr. High School, Jokihat Araria, Araria, (Bihar), India \\ Email: sandesh_official@yahoo.in
}

\begin{abstract}
The rapid rate of urbanization has led to the vast expansion of grey infrastructure in the National Capital Territory of Delhi. This dominance of grey infrastructure resulted in microclimatic changes such as urban heat island (UHI) effect and intensification of heatwave effectivity during the summer season in the NCT of Delhi. The series of micro-climatic changes compelled the policy makers to adopt the Leadership in Energy and Environmental Design (LEED) certification for all the Greenfield projects and grey field projects. The LEED certification promotes the "green" opportunities for reducing the negative impact the building has on the environment. The opportunities range from preventing erosion of topsoil, water contamination and creation of heat islands, effective use of a barren or wastelands etc. Most importantly, LEED uses what nature has given us by working with existing topography, plants and views. LEED focus on efficient urban design, use of renewable energy, deliberate mechanical and electrical system selection and proper commissioning and monitoring. Moreover, it also keeps the concept of 'Environmental Footprint' or 'Life Cycle Assessment' at the core while carrying out the work of Urban Design. The present research study begins with the assessment of the expansion of urban built-up during the period 1990-2015 in the NCT of Delhi. It is followed by the critical analysis of the need for LEED certification in the NCT of Delhi. Further, the study identifies the descriptive details like objectives, principles, aspects and other prospects of LEED certification. Lastly, the present research study carries out the critical analysis of major projects completed by LEED players so far. The study also depicts the role of LEED certification in the context of micro-climatic changes in the NCT of Delhi.
\end{abstract}

Key words: Micro-climatic Changes, Urban, Environmental Footprint, Green Opportunities

\section{Introduction}

The landscape of NCT of Delhi has undergone drastic changes from a rural area to an urban area due to rapid rate of urbanization. As per the Census of India, the urban area has increased from 46.21 percent (1991) to 75.09 percent (2011) while the rural area decreased from 53.79 percent (1991) to 24.91 percent (2011).Consequently, Urban Built Environment undergone expansion and is dominated by cultural features like Multi-storey Buildings (both Commercial and Industrial), Malls, Real Estate Township, Multi-Level Parking, Broad Roads, flyovers, Metro Rail with reduced 'Urban Open Spaces'. The increased urban area and the nature of Urban Built Environment in the NCT of Delhi has resulted in micro-climatic changes like Urban Heat Island Effect and the intensification of Heatwaves during the summer season. The policy planners, worried by these micro-climatic changes in the NCT of Delhi and other regions of India, set up Leadership in Energy and Environmental Design (LEED) certification in India from $1^{\text {st }}$ January 2007. It is an effort to develop cities on the current lines of sustainability through the development of sustainable urban neighbourhood. LEED is a sustainability assessment tool which regulates the sustainable approaches in urban design and urban planning. The integration of environmental, social and economic aspects is at the core of sustainability and popularly known as the 'Circle of Sustainability'. This is widely used in cities and urban settlements by a series of global organizations and it helps to improve the misunderstanding of sustainable urban design, which balances the social and economic effects of the built environment, while mitigating the environmental impacts. In the interpretation of sustainability, environmental concerns often gain more attention than social or economic factors. For comprehensive sustainability assessment purposes, there is a need for a means to ensure 
adequate attention to all important factors. The sustainability assessment framework, based on the circle of sustainability, interrelate the economic, social and environmental dimensions.

\section{Objectives of the Study}

The objectives of the research study are as follows:

- To assess the expansion of Urban Built-Up during the period 1990-2015 in the NCT of Delhi.

- To carry out the Critical analysis of need for LEED certification in India.

- To discuss the details (objectives, principles etc.) of Leadership in Energy and Environmental Design (LEED) certification.

\section{Database and Methodology}

To assess the expansion of urban built-up, the land use and land cover of the NCT of Delhi was carried out from satellite data of Landsat - 4,5 [Thematic Mapper (TM)], Landsat - 7 [Enhanced Thematic Mapper (ETM+)] and Landsat - 8 [Operational Land Imager (OLI) - Thermal Infrared

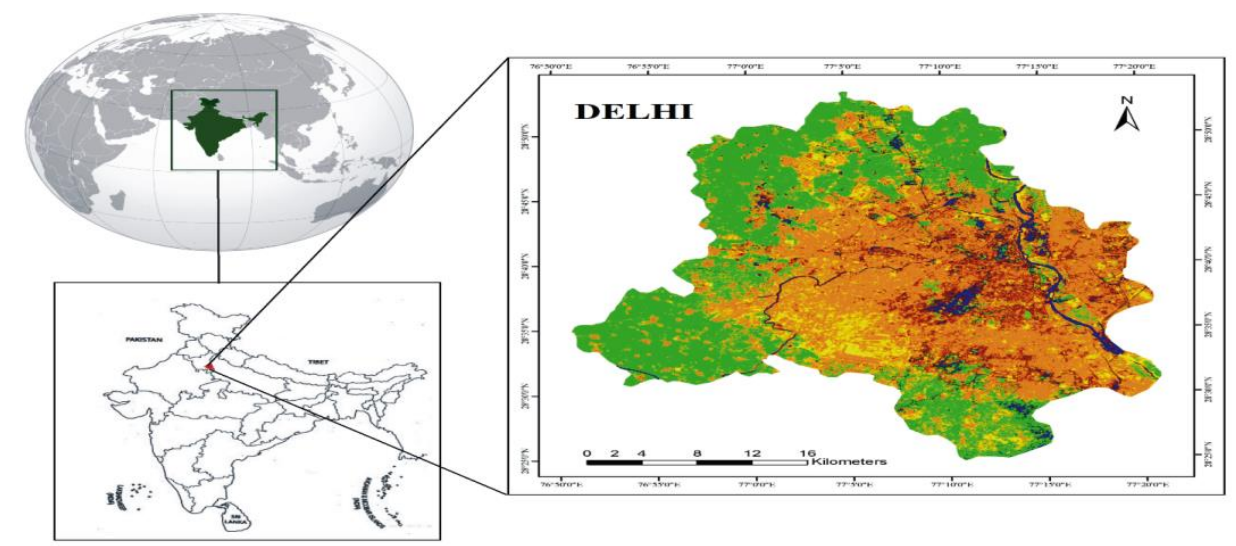

Sensors (TIRS)] for the three different time periods 1990, 2000 and 2015 (Table 1).

Figure 01: Location Map of Study Area, NCT of Delhi, India Source: Prepared by the Scholar

Table 01: Details of Satellite Imageries

\begin{tabular}{|l|c|l|l|l|l|l|c|c|}
\hline Satellite & Sens & \multicolumn{1}{|c|}{ Date } & \multicolumn{4}{|c|}{ Details } & \multicolumn{2}{c|}{ Bands } \\
\cline { 4 - 9 } & & & $\begin{array}{c}\text { Spatial } \\
\text { Resolution }\end{array}$ & $\begin{array}{c}\text { Thermal } \\
\text { Resolution }\end{array}$ & Path & Row & Spectral & Thermal \\
\hline Landsat-4,5 & TM & $7 / 11 / 1990$ & 30 meters & 120 meters & 147 & 40 & $1-5 \& 7$ & 6 \\
\hline Landsat-7 & ETM+ & $16 / 11 / 2000$ & 30 meters & 60 meters & 147 & 40 & $1-5 \& 7,8$ & 6 \\
\hline Landsat-8 & OLI & $9 / 11 / 2015$ & 30 meters & 100 meters & 147 & 40 & $1-9$ & 10,11 \\
\hline
\end{tabular}

Source: Landsat Data Users Handbook, Issues 1-8

\section{Data Source}

The satellite imageries of the NCT of Delhi for three different periods that is 1990, 2000, 2015 were obtained from the following sources: United States Geological Survey (USGS) and National Remote Sensing Centre (NRSC), Hyderabad, India.

\section{Tools of Analysis}

To calculate the 'Rate of Change Per Year', we will use the following formula (Chebet, C. 2013):

$$
R=\frac{\mathrm{Y}-\mathrm{X}}{\mathrm{T}}
$$

Where, $R=$ rate of change, $Y=$ the area $\left(\mathrm{km}^{2}\right)$ of the study area in the final year, $X=$ the area $\left(\mathrm{km}^{2}\right)$ of the study area in the initial year and $\mathrm{T}=$ the time difference in years.

\section{Software and Platforms}

The following software and platforms are involved in the present research study: ArcGIS ver. 9.1 and Office 365. 


\section{Expansion of Built-Up During the Period 1990-2015}

During the period 1990-2015, landscape of Delhi has been altered at a rapid rate. Consequently, the dominance of built-up in the Delhi is major characteristic feature of the land transformation during the above-mentioned period. The built-up through its expansion encroached the land area of other categories of land use and land cover viz. water bodies, vegetation, cropland, fallow land, riverbed. In other words, the shrinkage effect of other categories was balanced by the expansion of the built-up. During the period 1990-2000 (table 1 \& figure 2), the land use/land cover category which suffered major loss of land to built-up was fallow land and is depicted by purple colour in Figure 2. The prevalence of purple colour can be seen throughout the image and reflects the land transformation from fallow land to built-up. It can be inferred from the image that the peripheral region of NCT of Delhi experienced the maximum land transformation from fallow land to built-up. The second category of Land Use/Land Cover which experienced comparatively major land transformation to built-up was Crop Land and is depicted by the violet colour in Figure 2. The dominance of violet colour can be seen in the south-west region and reflects that cropland in this region experienced land transformation to built-up at considerable level. The third category is of vegetation which suffered a huge loss during the period 1990-2000. The land transformation under this category is depicted by the red colour on the image. The dominance of red colour can be seen in the north region, north-east region and south-east region and this shows that vegetation category has been degraded and transformed to built-up category. The last two categories of LULC that is waterbed and riverbed experienced marginal land transformation and are depicted by the yellow and brown colour respectively. During the period 2000-2015 (table 1 \& figure 2), the major category of land use/land cover which experienced large scale land transformation was vegetation and land transformation of this category is depicted by the red colour in Figure 2. The careful observation shows that red colour is dominant in the central region, north region, north east region, east region, and south- east region and it can be inferred that in the abovementioned regions experienced the loss of vegetation cover and expansion of built-up during the period 2000-2015. The second category of LULC which experienced comparatively huge land transformation is of Cropland and the dominance of violet colour in west region and northwest region shows that crop land got transformed to built-up in these regions. The other categories of Fallow land, water bodies and riverbed experienced marginal land transformation during the period 2000-2015.

Table 02: Area under Different LULC Categories (1990-2015), NCT of Delhi

\begin{tabular}{|l|c|c|c|c|c|c|}
\hline $\begin{array}{l}\text { Land Use/Land Cover } \\
\text { Categories }\end{array}$ & $\begin{array}{c}\mathbf{1 9 9 0} \\
\text { Area (ha) }\end{array}$ & \%age & $\begin{array}{c}\mathbf{2 0 0 0} \\
\text { Area (ha) }\end{array}$ & \%age & $\begin{array}{c}\mathbf{2 0 1 5} \\
\text { Area (ha) }\end{array}$ & \%age \\
\hline Water Bodies & 1899.4 & 1.3 & 1819.8 & 1.2 & 1583 & 1.1 \\
\hline Vegetation & 26402.8 & 30.4 & 37225.5 & 25.1 & 31675.3 & 21.3 \\
\hline Crop Land & 45118.8 & 17.8 & 25012.4 & 16.9 & 22468.7 & 15.1 \\
\hline Fallow Land & 10980.9 & 7.4 & 9519.6 & 6.4 & 5308.0 & 3.6 \\
\hline Riverbed & 1114.4 & 0.8 & 1016.2 & 0.7 & 1001.9 & 0.68 \\
\hline Built-Up & 62897.3 & 42.4 & 73819.5 & 49.7 & 86375.6 & 58.2 \\
\hline Total & $\mathbf{1 , 4 8 , 4 1 3 . 1}$ & $\mathbf{1 0 0 . 0}$ & $\mathbf{1 , 4 8 , 4 1 3 . 1}$ & $\mathbf{1 0 0 . 0}$ & $\mathbf{1 , 4 8 , 4 1 3 . 1}$ & $\mathbf{1 0 0 . 0}$ \\
\hline
\end{tabular}

Source: Calculated and Compiled by the Scholar from Landsat satellite imageries of 1990, 2000 and 2015

Table 03: NCT of Delhi: 'Rate of Change' of Land Use and Land Cover, 1990-2015

\begin{tabular}{|c|l|c|c|c|c|}
\hline$\#$ & LULC Classes & $\begin{array}{c}\mathbf{1 9 9 0 - 2 0 0 0} \\
\text { Area (ha) }\end{array}$ & $\begin{array}{c}\mathbf{2 0 0 0 - 2 0 1 5} \\
\text { Area (ha) }\end{array}$ & $\begin{array}{c}\mathbf{1 9 9 0 - 2 0 1 5} \\
\text { Area (ha) }\end{array}$ & $\boldsymbol{R}=\frac{\mathbf{Y}-\mathbf{X}}{\mathbf{T}}$ \\
\hline 1 & Water Body & -79.6 & -236.3 & -315.9 & -12.636 \\
\hline 2 & Vegetation & -7892.8 & -5550.2 & -13443 & -537.72 \\
\hline 3 & Cropland & -1390.4 & -2543.7 & -3934.1 & -157.364 \\
\hline 4 & Fallow land & -1461.3 & -4211.6 & -5672.9 & -226.916 \\
\hline 5 & Riverbed & -98.2 & -14.3 & -112.5 & -4.5 \\
\hline 6 & Built-Up & +10922.2 & +12556.1 & +23478.3 & +939.132 \\
\hline
\end{tabular}

Source: Calculated and Compiled by the scholar

Rate of Change' of Various Categories to Built-Up during 1990-2015

The 'Rate of Change' of land for the category of built-up was +939.132 during the period 19902015 (Table 3 and Figure 3). The built-up area increased to 10,922.2 hectares and 12,556.1 hectares during the period $1990-2000$ and 2000-2015 respectively. On a whole, there was an 
increase of $23,478.3$ hectares of land area under the category of built-up during the period 1990-2015 in Delhi. Among categories of LULC, vegetation with highest 'Rate of Change' that is -537.72 faced large scale loss of land followed by the fallow land (-226.916), cropland (157.364), water body (-12.636) and riverbed (-4.5). The shrinking effect of the above categories of land use/land cover is equalized by the expansion of built-up in Delhi. The fact can be proved by summing up all the negative values of 'Rate of Change' and comparing the resultant value with the positive value of 'Rate of Change' of built-up.

Figure 02: Built-Up Expansion Maps 1990-2000, 2000-2015 and 1990-2015, NCT of Delhi

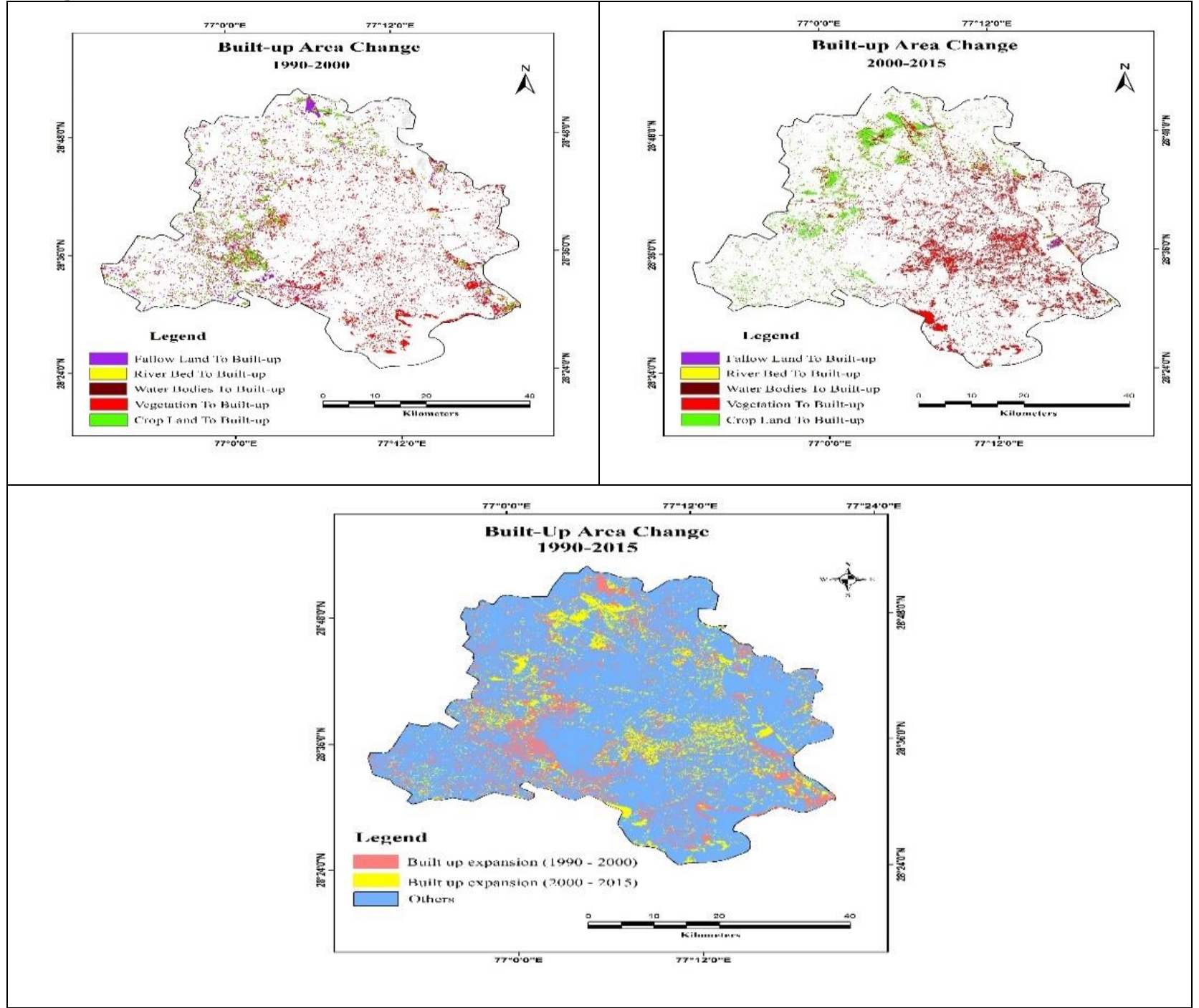

Source: Landsat Imagery, 1990, 2000 and 2015.

Note: Positive sign (+) indicates an increase while the Negative sign (-) indicates decrease in area.

Figure 3: 'Rate of Change' of Various Land Use and Land Cover Classes, 1990-2015

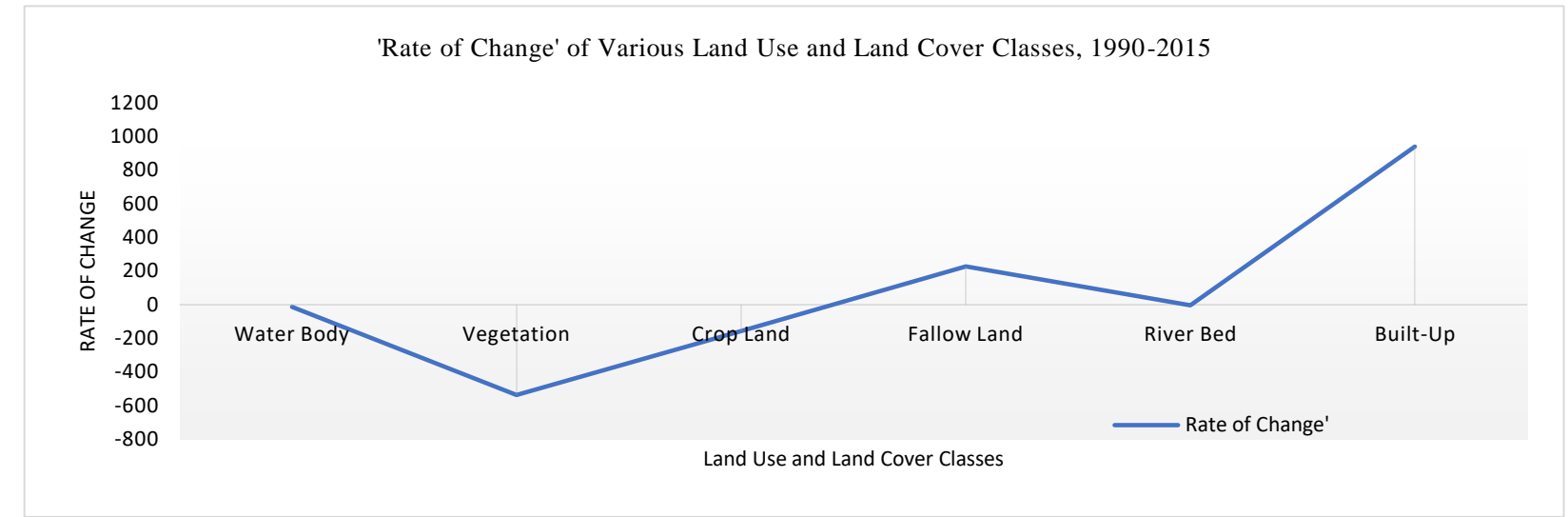

Source: Prepared by the Scholar 


\section{What is the Need of LEED Certification in India?}

Over-expansion of grey infrastructure due to urbanization has induced micro-climatic changes in the form of Urban Heat Island (UHI) effect in the NCT of Delhi. The UHI effect results in thermal discomfort (both indoor and outdoor) and increased energy consumption in airconditioned buildings. It is estimated that 3 percent to 8 percent higher electricity demand in cities with populations greater than $1,00,000$ is used to comfort the heat due to the heat island effect (Green in Practice, 103 - Cool Communities, 2012).

The solar energy in the form of solar radiations falls on the surface of cultural features like buildings, roads. The part of this incoming solar radiation is reflected into space as solar reflectance of the surfaces due to reflectivity while the remaining part of solar radiation is absorbed and results in heating of cultural features and on heating, cultural features emit infrared radiations due to emissivity. During this process, air temperature is increased due to absorption of solar radiation by the atmosphere and the heat emitted by different surfaces while surface temperature is increased due to solar radiation and the solar reflectance of the surfaces. Surface Temperature plays a major role in the Urban Heat Island (UHI) effect because of hot surfaces of the cultural features emit heat in the surroundings which in turn increases the air temperature and thus, making surroundings much warm as compared to the rural counterpart. Urban Heat Island (UHI) effect is the result of a combination of several factors like more heat-absorbing surfaces (Rooftops, Buildings and Paved Surfaces), the trapping of hot air between buildings, limited tree cover and other heat-trapping and heat-inducing factors such as fuel combustion and air conditioning can result in average annual temperatures in urban areas being $1-3^{\circ} \mathrm{C}$ hotter than surrounding areas. This Urban Heat Island (UHI) effect is observed during night in the summer season in the NCT of Delhi. Urban Heat Island (UHI) effect intensifies the heatwaves during summer in the urban areas and consequently, residents are exposed to higher temperatures during the day as well as night.

The higher urban temperature means i) greater energy use during the summer, ii) Increased air pollution and Green House Gas emissions, iii) Negative effects of higher temperatures on human health and comfort and iv) warmer storm water run-off affecting water quality. If all buildings in urban areas were made to adopt green Building concepts, India could have saved more than $8400 \mathrm{MW}$ of power which is enough to light half of Delhi or 5.5 lakh homes a year per estimates by TERI. A green building depletes very little of the natural resources during its construction and operation. The aim of a green building design is to minimize the demand on non-renewable resources and maximize the utilization efficiency of these resources when in use and utilization of renewable resources.

The green building rating system is an evaluation tool that measures the environmental performance of a building through its life cycle. Building rating systems are a popular tool to bring momentum in achieving energy efficiency and sustainability in buildings. In India, at present, there are predominantly two rating systems to certify buildings as green buildings, namely LEED. This rating system has a predefined set of criteria and there are points for each one of these criteria. The buildings are required to fulfil the defined criteria and achieve a certain number of points to be certified.

\section{Important Criterions under LEED - India}

The important criterions under the LEED-India Green Building Certification System (table 4)include i) Sustainable Sites, ii) Water Efficiency, iii) Energy and Atmosphere, iv) Materials and Resources, v) Indoor Environmental Quality and vi) Innovations and Design Process.

Table 04: Important Criterions and Point Allocations, LEED-India

\begin{tabular}{|c|l|c|}
\hline$\#$ & \multicolumn{1}{|c|}{ Criterions } & Points Allocation \\
\hline & Pre-Requisites & 8 \\
\hline 1 & Sustainable Sites & 13 \\
\hline 2 & Water Efficiency & 6 \\
\hline 3 & Energy and Atmosphere & 17 \\
\hline 4 & Materials and Resources & 13 \\
\hline 5 & Indoor Environmental Quality & 15 \\
\hline 6 & Innovations and Accredited Prof. Points & 5 \\
\hline & Total & 69 \\
\hline
\end{tabular}

Source: LEED 2011 for India, Manual, 2011 
Soil erosion and sedimentation control are the pre-requisite which should be taken into consideration before selecting the Sustainable Site. The intention is to minimize impact on water quality and air quality (Table 4). The selection of 'Sustainable Sites' is based on the basic principle which states that time and nature have sculpted the land. In other words, we are supposed to develop within the existing topography, plants and views despite digging and levelling of land, clearing of forest and alteration of views. The sustainable sites section of LEED - India outlines various 'Green Opportunities' for reducing the negative impact the building has on the environment. The opportunities range from preventing erosion of topsoil, water contamination and creation of heat islands, effective use of a barren or wastelands etc.

Table 05: Credits under Sustainable Site, LEED-India

\begin{tabular}{|l|l|c|}
\hline \multicolumn{1}{|c|}{ Credit } & Title & Points \\
\hline Pre-Requisite 1 & Erosion and Sedimentation Control & 1 \\
\hline Credit 1 & Site Selection & 1 \\
\hline Credit 2 & Development Density and Community Connectivity & 1 \\
\hline Credit 3 & Brownfield and Re-development & 1 \\
\hline Credit 4 & Alternative Transportation & $1-3$ \\
\hline Credit 5 & Site Development & $1-2$ \\
\hline Credit 6 & Storm Water Design & $1-2$ \\
\hline Credit 7 & Heat Islands Effect & $1-2$ \\
\hline Credit 8 & Light Pollution Reduction & 1 \\
\hline & Total & $\mathbf{1 3}$ \\
\hline
\end{tabular}

Source: LEED 2011 for India, Manual, 2011

'Water Efficiency' can be defined as the accomplishment of a function, task, process, or result with the minimal amount of water feasible (Table 6). It is an indicator of the relationship between the amount of water required for a purpose and the amount of water used or delivered. Water efficiency differs from water conservation in that it focuses on reducing waste. A proposition is that the key for efficiency is reducing waste not restricting use. It also emphasizes that influence consumers can have in water efficiency by making small behavioural changes to reduce water- wastage and by choosing more water-efficient products. Examples of water-efficient steps include simple measures like fixing leaking taps.

Table 06: Credits under Water Efficiency, LEED-India

\begin{tabular}{|l|l|c|}
\hline \multicolumn{1}{|c|}{ Credit } & \multicolumn{1}{|c|}{ Title } & Points \\
\hline Credit 1 & Water Efficient Landscaping & $1-2$ \\
\hline Credit 2 & Water Efficiency in A/C Systems & 1 \\
\hline Credit 3 & Innovative Wastewater Technologies & 1 \\
\hline Credit 4 & Water Use Reduction & $1-2$ \\
\hline & Total & $\mathbf{6}$ \\
\hline
\end{tabular}

Source: LEED 2011 for India, Manual, 2011

'Energy and Atmosphere' section of LEED - India lays emphasis on efficient design, use of renewable energy, deliberate mechanical and electrical system selection, and proper commissioning and monitoring. Using energy is a cornerstone of sustainable design (table 7).

Table 07: Credits under Energy and Atmosphere, LEED-India

\begin{tabular}{|l|l|c|}
\hline \multicolumn{1}{|c|}{ Credit } & Title & Points \\
\hline Pre-Requisite 1 & Fundamental Building Systems Commissioning & $\mathrm{R}^{*}$ \\
\hline Pre-Requisite 2 & Minimum Energy Performance & $\mathrm{R}^{*}$ \\
\hline Pre-Requisite 3 & CFC Reduction in HVAC \& R Equipment & $\mathrm{R}^{*}$ \\
\hline Credit 1 & Optimized Energy Performance & $1-10$ \\
\hline Credit 2 & Renewable Energy & $1-3$ \\
\hline Credit 3 & Additional Commissioning & 1 \\
\hline Credit 4 & Ozone Depletion & 1 \\
\hline Credit 5 & Measurement and Verification & 1 \\
\hline Credit 6 & Green Power & 1 \\
\hline \multicolumn{2}{|c|}{ Total } & $\mathbf{1 7}$ \\
\hline
\end{tabular}

The 'Materials and Resources' are in the picture from the first round of planning to the final stages of demolition or renovation of a building or product (table 8 ). Of all the criteria 
covered by LEED - India, Materials and Resources has perhaps the broadest application and relevance. They are the ingredients and choosing them wisely makes all the difference in terms of the overall impact of the building throughout its life. This is where 'Environmental Footprint' or 'Life Cycle Assessment' comes into play. The study shows that 40 percent of the Carbon Dioxide that contributes to our warming planet comes from buildings. While some of it is a secondary effect of operational needs such as electricity, air-conditioners and heating, many Green House Gases (GHG's) arise from resource extraction, manufacturing and production of the building materials themselves.

Table 08: Credits under Materials and Resources, LEED-India

\begin{tabular}{|l|l|c|}
\hline \multicolumn{1}{|c|}{ Credit } & Title & Points \\
\hline Pre-Requisite 1 & Storage and Collection of Recyclables & $\mathrm{R}^{\star}$ \\
\hline Credit 1 & Construction Waste Management & 3 \\
\hline Credit 2 & Resource Reuse & 2 \\
\hline Credit 3 & Recycled Content & 2 \\
\hline Credit 4 & Local/Regional Materials & 2 \\
\hline Credit 5 & Rapidly Renewable Material & 1 \\
\hline Credit 6 & Certified Wood Total & 1 \\
\hline \multicolumn{2}{|c|}{} \\
\multicolumn{2}{|c|}{ Source: LEED 2011 for India, Manual, 2011 } & 13 \\
\hline
\end{tabular}

'Indoor Environmental Quality' (IEQ) addresses the subtle issues that influence, how we feel in a space (Table 9). Building green means considering not only the environmental impact of materials and construction but also the physical and psychological health of the occupants. Some can argue that it is not desirable, but also a fundamental human right to live and work in spaces with healthy indoor environments. Buildings enhance people's lives when they permit ample air circulation, maintain clean air and comfortable temperatures, and allow individuals to have a sense of control over their own indoor experience.

Table 09: Credits under Indoor Environmental Quality (IEQ), LEED-India

\begin{tabular}{|l|l|c|}
\hline \multicolumn{1}{|c|}{ Credit } & \multicolumn{1}{|c|}{ Title } & Points \\
\hline Pre-Requisite 1 & Minimum IAQ Performance & $\mathrm{R}$ \\
\hline Pre-Requisite 2 & Environmental Tobacco Smoke (ETS) Control & $\mathrm{R}$ \\
\hline Credit 1 & Outdoor Air Delivery Monitoring & 1 \\
\hline Credit 2 & Increased Ventilation & 1 \\
\hline Credit 3 & Construction IAQ Management Plan & 2 \\
\hline Credit 4 & Low-Emitting Material & 4 \\
\hline Credit 5 & Indoor Chemical and Pollutant Source Control & 1 \\
\hline Credit 6 & Controllability of System & 2 \\
\hline Credit 7 & Thermal Control & 2 \\
\hline Credit 8 & Daylight and Views Total & 2 \\
\hline & \multicolumn{1}{c|}{ Tol } \\
\hline
\end{tabular}

Source: LEED 2011 for India, Manual, 2011

Note: ${ }^{*} \mathrm{R}=$ Required

'Manufacturing' to demonstrate its commitment to public health and the environment by producing better, safer products. Further, optimized utilization of raw material to conserve natural resource (table 10).

Table 10: Credits under Innovations and Design, LEED-India

\begin{tabular}{|l|l|c|}
\hline \multicolumn{1}{|c|}{ Credit } & \multicolumn{1}{|c|}{ Title } & Points \\
\hline Credit 1 & Innovation in Design & 4 \\
\hline Credit 2 & LEEDTM Accredited & 1 \\
\hline & Professional Total & 5 \\
\hline
\end{tabular}

Source: LEED 2011 for India, Manual, 2011

\section{Certification Levels of LEED in India}

LEED is used as a design guideline and third-party certification tool; it aims to improve occupant well-being, environmental performance and economic returns of buildings using established and innovative practices, standards and technologies. LEED is like a checklist of credits that can be achieved in the above discussed major categories. LEED evaluates a building for sustainability objectives it achieves and recognizes building at four certification level (table 11). LEED is one of the most successful green building rating systems in the world because of its early market penetration and adoption by professionals. This rating system is 
based on accepted energy and environmental principles and strikes a balance between known established practices and emerging concepts. It is performance-oriented, wherein credits are earned for satisfying criteria addressing specific environmental impacts inherent in the design and construction. Different levels of green building certification are awarded based on the total credits earned. The system is designed to be comprehensive in scope, yet simple in application. The specific credits in the rating system provide guidelines for the design and construction of buildings of all sizes in both the public and private sectors.

Table 11: Certification Levels of LEED in India

\begin{tabular}{|c|l|c|}
\hline$\#$ & \multicolumn{1}{|c|}{ Rating } & Points \\
\hline 1 & LEED Certified & $26-32$ \\
\hline 2 & LEED Certified Silver Level & $33-38$ \\
\hline 3 & LEED Certified Gold Level & $39-51$ \\
\hline 4 & LEED Certified Platinum Level & $52-69$ \\
\hline
\end{tabular}

Source: LEED 2011 for India, Manual, 2011

Till date, there are about 650 LEED-certified projects in India and 4500 more have registered for certification. Chennai with 45 buildings under LEED certification leads the Indian cities (Table 12).

Table 12: Major Projects with LEED Certifications in India till Date

\begin{tabular}{|c|l|l|}
\hline$\#$ & \multicolumn{1}{|c|}{ Rating } & \multicolumn{1}{|c|}{ Name of Project } \\
\hline 1 & Platinum Rated & Cll - Godrej GBC, Hyderabad \\
& & ITC Green Centre, Gurgaon \\
2 & & Wipro Technologies, Gurgaon \\
\hline 3 & \multirow{2}{*}{ Gold Rated } & IGP Office, Gulbarga \\
\cline { 3 - 3 } & & NEG Micon, Chennai \\
\cline { 3 - 4 } & & Grundfos Pumps, Chennai \\
\hline 6 & Silver Rated & L\&T EDRC, Chennai \\
\hline 7 & &
\end{tabular}

Source: LEED 2011 for India, Manual, 2011

\section{Conclusion}

LEED promotes rainwater harvesting, solar Photo-Voltaic (PV) installation, construction waste management, energy efficiency and several other techniques which minimize the impact of grey infrastructure on micro-climate of a region. The NCT of Delhi is already facing the problem of Urban Heat Island effect and the intensification of heatwave effectivity during the summer season and therefore, if followed properly then LEED certification will resolve the problem of micro-climatic changes to a greater extent in the NCT of Delhi. LEED certification is applicable on Greenfield projects, grey field projects, brown field projects and so, LEED certification must be made mandatory for all projects whether private or public.

\section{References}

1. Bo Xia1; Jian Zuo; Martin Skitmore; Stephen Pullen; and Qing Chen (2013) "Green Star Points Obtained by Australian Building Projects." Journal of Architectural Engineering, Vol. 19, No. 4, December 1, OASCE, ISSN 1076-0431/2013/4-302-308

2. Census of India $(1990,2001,2011)$ Government of India, India.

3. Chebet, C. (2013) An Assessment of Land Use and Land Cover in and around Kakamega Forest in Kenya using GIS and Remote Sensing, Journal of Emerging Trends in Engineering and Applied Sciences, Vol.4, 1, 46-53.

4. J. T. Kevern, A.M. (2011) ASCE "Green Building and Sustainable Infrastructure: Sustainability Education for Civil Engineers." Journal of Professional Issues in Engineering Education and Practice, Vol. 137, No.2, April 1, 2011. CASCE, ISSN 1052-3928/2011/2-1.

5. Leadership in Energy and Environmental Design (LEED) for India, Manual, 2011

6. Ninza Z. Khanna, John Roman Kiewicz, Nan Zhou and Wei Feng (2013) "From platinum to three stars: Comparative analysis of U.S. and China green building rating programs" ACEEE summer study on energy efficiency in buildings. 2-402-414.

7. Peng wu1 and Sui Pheng low "Project Management and Green Buildings: Lessons from the Rating Systems." Journal of Professional Issues in Engineering Education and Practice, Vol. 136, No. 2, April 1, 2010. (OASCE, ISSN 1052-3928/2010/2-64-70

8. R.G. Saigaonkar, S.S. Pimplicar, P.D. Aher, (2014) "Unique rating system for green building; By comparing various existing rating systems" ISSN: 2248-9622, Vol. 4, Issue 1 (Version 2), Jan 2014, 197-206

9. Vyas Gayatri Sachin and Jha K. N. (2012) "Comparative study of rating systems for green building in developing and developed countries" ICCIDC-III July 4-6,2012, Bangkok, Thailand. 